\title{
Correction to: Priorities of a "good death" according to cancer patients, their family caregivers, physicians, and the general population: a nationwide survey
}

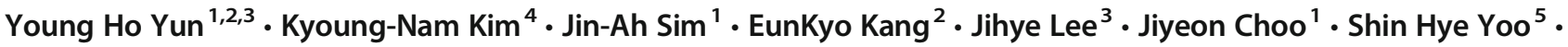 \\ Miso Kim ${ }^{5}$. Young Ae Kim ${ }^{6}$. Beo Deul Kang ${ }^{7}$. Hyun-Jeong Shim ${ }^{8}$. Eun-Kee Song ${ }^{9} \cdot$ Jung Hun Kang $^{10}$. \\ Jung Hye Kwon ${ }^{11}$. Jung Lim Lee ${ }^{12}$. Soon Nam Lee ${ }^{13}$. Chi Hoon Maeng ${ }^{14}$. Eun Joo Kang ${ }^{15}$. Young Rok Do ${ }^{16}$. \\ Yoon Seok Choi ${ }^{17} \cdot$ Kyung Hae Jung ${ }^{18}$
}

Published online: 16 July 2019

(C) Springer-Verlag GmbH Germany, part of Springer Nature 2019

Correction to: Support Care Cancer (2018) 26:3479-3488
https://doi.org/10.1007/s00520-018-4209-y

In the October 2018 edition of the Supportive Care in Cancer (26(10):3479-3488), we published an article entitled "Priorities of a "good death" according to cancer patients, their family caregivers, physicians, and the general population: a nationwide survey." While recently extending that research, however, we discovered that 236 members of the general population were mistakenly duplicated by the investigating agency (World Research) and 1241 were reported rather than 1005 . Here, we present corrections and discuss the relevant data.

In the abstract, the results paragraph (page 3479) should be corrected to the following:

"Treatment choices" followed, "mentally aware," "finances in order," and "die at home" were found to be the least important components among all four groups.

In the body of the paper, the first paragraph of the "Results" section (page 3481) should be corrected to the following:

A total of 3940 individuals - 1001 cancer patients and 1006 family caregivers from the 12 hospitals, and 928 physicians from the 12 hospitals and the KMA (the three stakeholder groups), and 1005 members of the general Korean population-participated in this study. Table 1 shows the socio-demographic characteristics of the respondents. There

The online version of the original article can be found at https://oi.org/ 10.1007/s00520-018-4209-y

Young Ho Yun

lawyun@snu.ac.kr

Extended author information available on the last page of the article were more female respondents in all groups except for the physician group, and the average age of respondents was 46 .

Our original Table 1 (page 3482) should be corrected to the following:

Our original Table 2 (page 3482) should be corrected to the following:

Our original Table 3 (page 3483) should be corrected to the following:

Our original Table 4 (page 3485) should be corrected to the following:

Our original Table 5 (page 3486) should be corrected to the following:

In the results of the paper, the right side of the "Results" section (page 3483) should be corrected to the following:

Factors considered important to a good death by attitude toward death

Table 4 shows the associations between five attitudes toward dying and death and the factors of a good death. "Not be a burden to family" and "resolve unfinished business" were associated with the attitude that death was the ending of life. "Feel life was meaningful" was significantly associated with the negative attitude that death was painful and to be feared. The attitude of being remembered was associated with "freedom from pain."

In the results of the paper, the left side of the "Results" section (page 3484) should be corrected to the following:

Multivariate logistic regression models for factors considered important to a good death by sociodemographic factors and attitudes toward dying and death

By integrating two previous models, we performed stepwise multivariate logistic regression analyses for factors considered important to a good death by sociodemographic factors and by attitude toward dying and death (Table 5). "Presence of family" was inversely associated with age $\geq$ 
Table 1 Sociodemographic characteristics of the 3940 participants in a survey

\begin{tabular}{|c|c|c|c|c|c|}
\hline Characteristic & & $\begin{array}{l}\text { General population, } \\
n=1005 \\
\text { No. }(\%)\end{array}$ & $\begin{array}{l}\text { Cancer patients, } \\
n=1001 \\
\text { No. }(\%)\end{array}$ & $\begin{array}{l}\text { Family caregivers, } \\
n=1006 \\
\text { No. }(\%)\end{array}$ & $\begin{array}{l}\text { Physicians, } \\
(n=928) \\
\text { No. }(\%)\end{array}$ \\
\hline \multirow[t]{2}{*}{ Sex } & Male & $494(49.2)$ & $390(39.0)$ & $324(32.2)$ & $565(60.9)$ \\
\hline & Female & $511(50.9)$ & $610(60.9)$ & $682(67.8)$ & $363(39.2)$ \\
\hline \multirow[t]{3}{*}{ Age, years } & $<40$ & $366(36.4)$ & $123(12.3)$ & $292(29.05)$ & $612(66.0)$ \\
\hline & $40-49$ & $209(20.8)$ & $211(21.1)$ & $304(30.25)$ & $222(23.9)$ \\
\hline & $\geq 50$ & $430(42.8)$ & $667(66.6)$ & 409 (40.7) & $94(10.1)$ \\
\hline \multirow[t]{3}{*}{ Education } & Middle school or less & $152(15.1)$ & $205(20.5)$ & $75(7.5)$ & $0(0)$ \\
\hline & High school & $397(39.5)$ & $433(43.3)$ & 401 (39.9) & $0(0)$ \\
\hline & College or higher & $456(45)$. & $363(36.3)$ & $530(52.7)$ & $928(100)$ \\
\hline \multirow[t]{2}{*}{ Employed } & No & $316(34.2)$ & $737(74.1)$ & $569(56.6)$ & $0(0)$ \\
\hline & Yes & $607(65.8)$ & 257 (25.9) & 437 (43.4) & $928(100)$ \\
\hline \multirow[t]{2}{*}{ Religion } & No & $587(58.4)$ & $462(46.2)$ & $494(49.1)$ & $386(42.0)$ \\
\hline & Yes & 418 (41.6) & $539(53.8)$ & $512(50.9)$ & $540(58.7)$ \\
\hline \multirow{4}{*}{$\begin{array}{l}\text { Monthly income, in } 1000 \\
\text { Korean won }\end{array}$} & $<2000$ & $119(11.8)$ & $260(26.0)$ & $117(11.6)$ & $0(0)$ \\
\hline & 2000-2999 & $162(16.1)$ & $196(19.6)$ & $183(18.2)$ & $0(0)$ \\
\hline & $3000-3999$ & $301(30.0)$ & $217(21.7)$ & $260(25.8)$ & $0(0)$ \\
\hline & $\geq 4000$ & $423(42.1)$ & $328(32.8)$ & $446(44.3)$ & $928(100)$ \\
\hline \multirow[t]{2}{*}{ Health insurance } & $\begin{array}{l}\text { National Health } \\
\text { Insurance }\end{array}$ & 979 (97.4) & 948 (94.6) & $981(97.5)$ & $928(100)$ \\
\hline & Medicaid & $26(2.6)$ & $53(5.3)$ & $25(2.5)$ & $0(0)$ \\
\hline
\end{tabular}

50 years and presence of religion but positively associated with higher educational status. Age $\geq 50$ years, lower educational status, comorbidity, positive attitude toward death as the end of life, and negative attitude toward death as painful were associated with "not be a burden to family." The third factor, "resolve unfinished business," was positively associated with female sex, older age, and attitude that death was the ending of life and attitude that death was painful, but negatively associated with the attitude that the dying should forgive those who have offended or hurt them.

In the "Discussion" section, the first sentence of third paragraph (page 3487) should be corrected to the following:

Our finding that "resolve businesses was more often considered to be important among female, older, lower-educated respondents are in contrast to the results that 'feel life was meaningful" was more often considered to be important

Table 2 Ranking in importance of the components of a good death by the 4 participating groups

\begin{tabular}{|c|c|c|c|c|c|}
\hline Component & $\begin{array}{l}\text { Total }^{\mathrm{a}} \\
(n=3940)\end{array}$ & $\begin{array}{l}\text { General population }{ }^{\mathrm{b}} \\
(n=1005)\end{array}$ & $\begin{array}{l}\text { Cancer patients } \\
(n=1001)\end{array}$ & $\begin{array}{l}\text { Family caregivers }{ }^{\mathrm{b}} \\
(n=1006)\end{array}$ & $\begin{array}{l}\text { Physicians }^{\mathrm{b}} \\
(n=928)\end{array}$ \\
\hline Presence of family & $1027(24.9)$ & $22.4(2)$ & $24.5(2)$ & $25.9(1)$ & $27.1(2)$ \\
\hline Not be a burden to family & $856(22.3)$ & $22.6(1)$ & $27.7(1)$ & $25.5(2)$ & $12.9(3)$ \\
\hline $\begin{array}{l}\text { Resolve unfinished } \\
\text { business }\end{array}$ & $678(17.7)$ & $20.4(3)$ & $18.8(3)$ & $20.8(3)$ & $10.3(5)$ \\
\hline Feel life was meaningful & $537(13.4)$ & $10.3(5)$ & $7.9(5)$ & $8.7(5)$ & $27.8(1)$ \\
\hline Freedom from pain & $408(10.3)$ & $14.1(4)$ & $11.9(4)$ & $9.5(4)$ & $5.0(6)$ \\
\hline At peace with God & $228(6.2)$ & $4.1(6)$ & $4.8(6)$ & $5.4(6)$ & $11.0(4)$ \\
\hline Treatment choices & $60(1.6)$ & $1.1(9)$ & $1.5(7)$ & $1.2(8)$ & $2.7(7)$ \\
\hline Mentally aware & $52(1.3)$ & $0.5(10)$ & $1.1(9)$ & $1.3(7)$ & $2.2(8)$ \\
\hline Finances in order & $50(1.2)$ & $2.5(7)$ & $0.7(10)$ & $0.9(9)$ & $0.8(9)$ \\
\hline Die at home & $44(1.1)$ & $2.1(8)$ & $1.2(8)$ & $0.9(9)$ & $0.1(10)$ \\
\hline
\end{tabular}

${ }^{\text {a }}$ Values are presented as $n(\%)$ for total counts

${ }^{\mathrm{b}}$ Values are presented as \% (rank) for participant group 


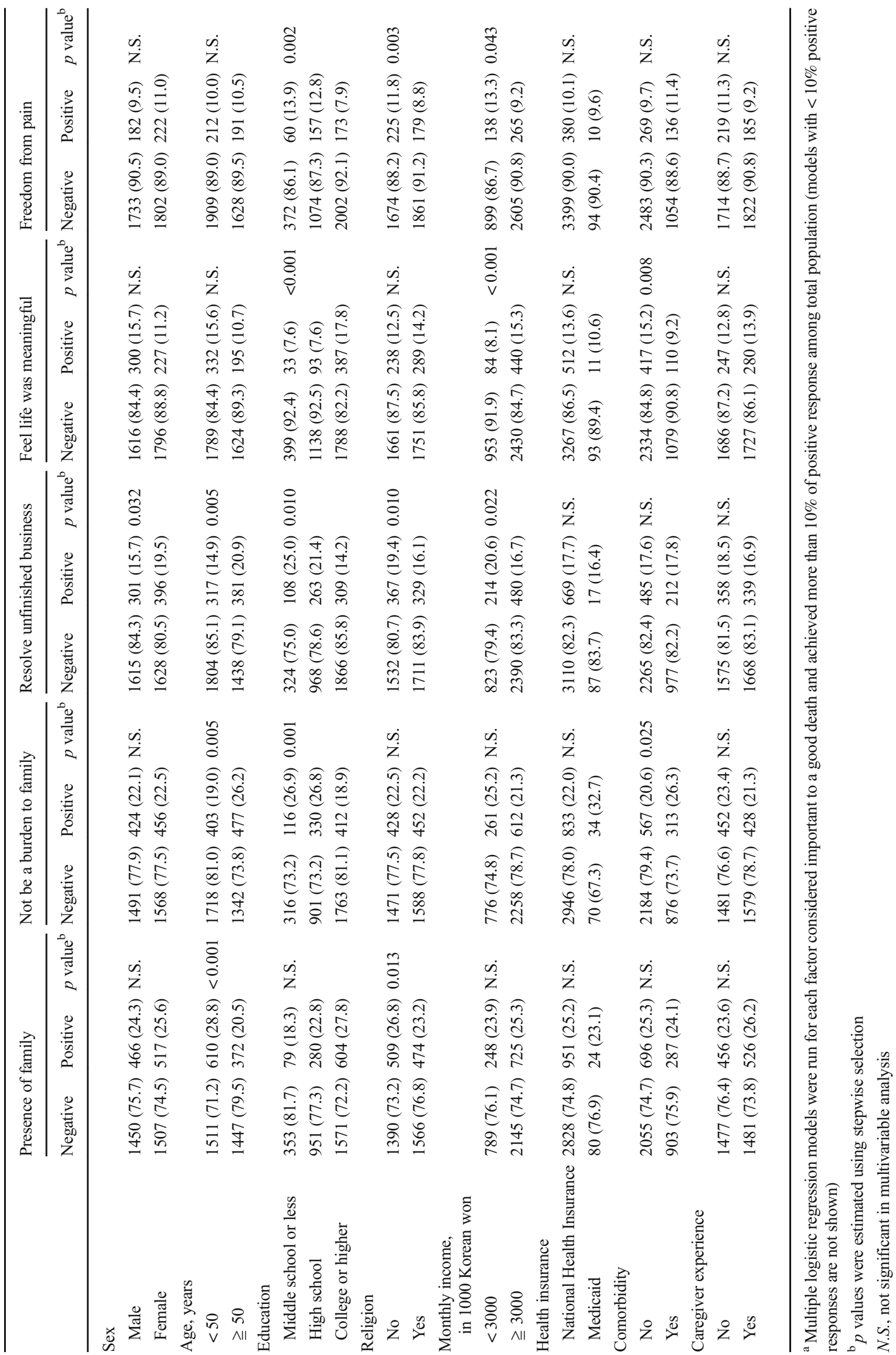




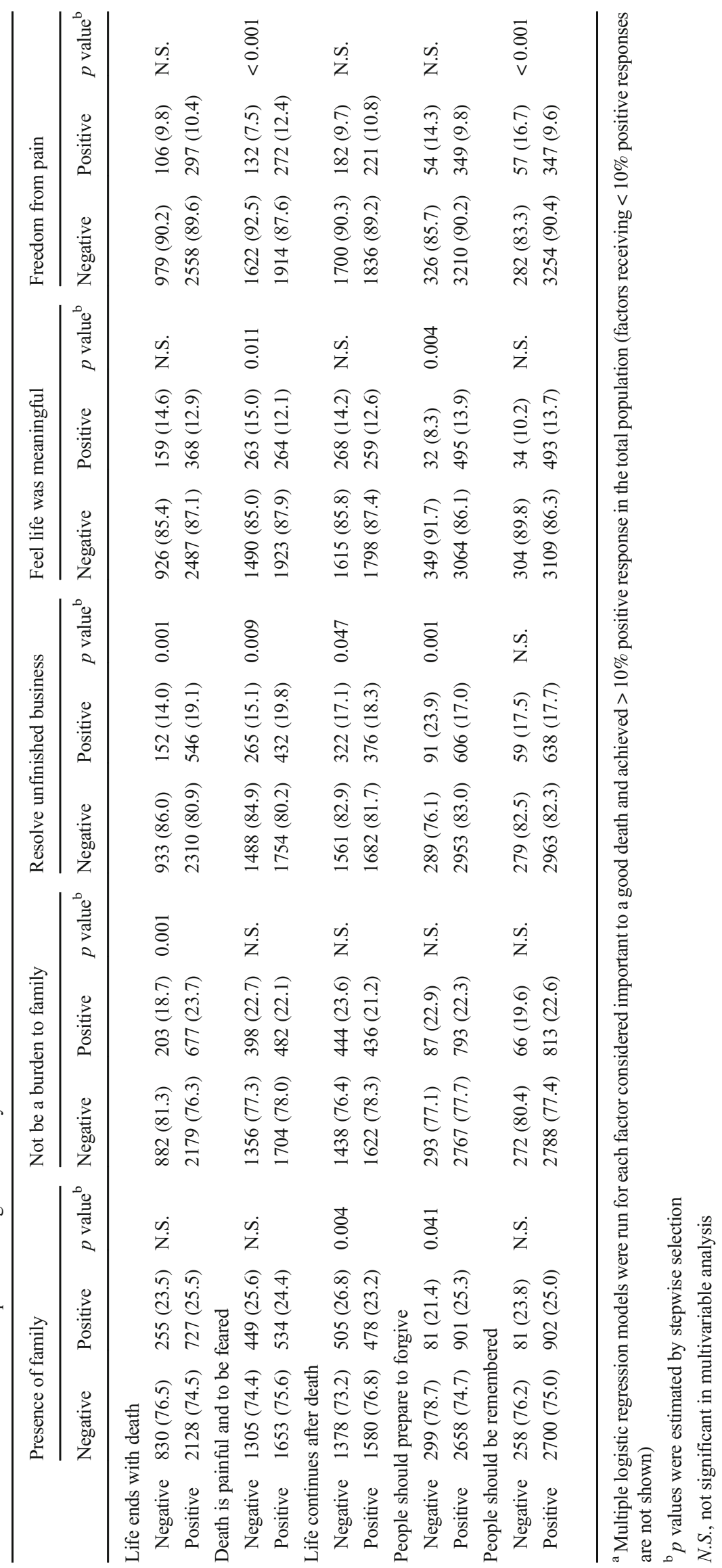




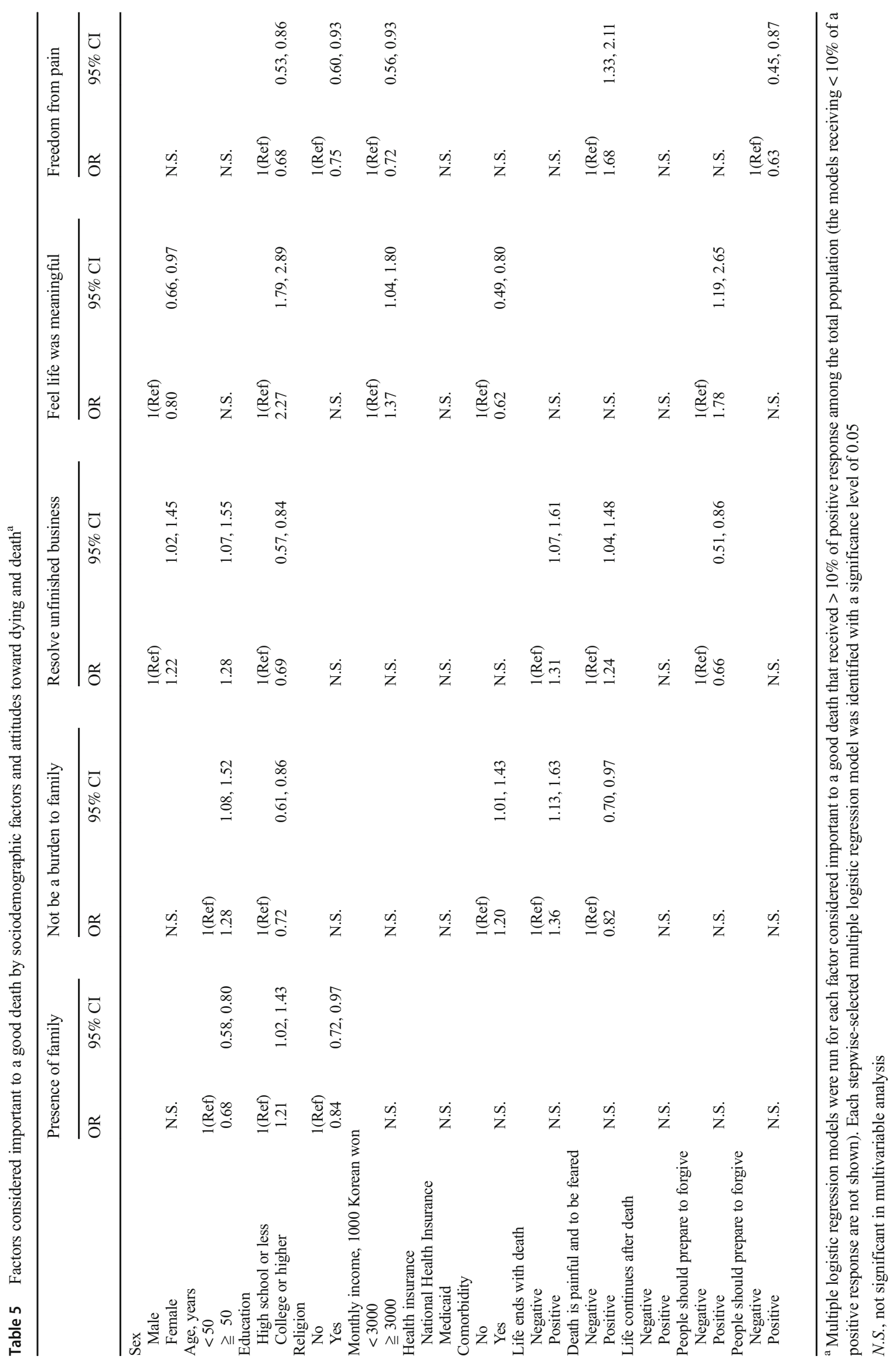


among male, higher-educated, high-income respondents without comorbidity.

In the Discussion section, the first sentence of the fourth paragraph (page 3487) should be corrected to the following:

Another interesting finding was that attitudes toward dying and death_-"life ends with death," "death is painful," and "people should prepare to forgive"-were associated with participants' opinions of the components of a good death.

In the limitation of the "Discussion" section, the second sentence of the last paragraph (page 3487) should be corrected to the following:
First, although we administered nationwide questionnaires to four groups that included 3940 individuals, patients and family caregivers were recruited from 12 general hospitals, so generalization of the findings should be made cautiously.

We wish to apologize to the publisher and readers of Supportive Care in Cancer for these errors.

Publisher's note Springer Nature remains neutral with regard to jurisdictional claims in published maps and institutional affiliations.

\section{Affiliations}

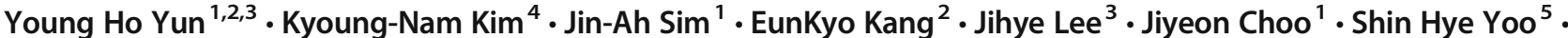 Miso Kim ${ }^{5}$ • Young Ae Kim ${ }^{6}$ • Beo Deul Kang ${ }^{7} \cdot$ Hyun-Jeong Shim ${ }^{8}$ • Eun-Kee Song ${ }^{9}$. Jung Hun Kang ${ }^{10}$.

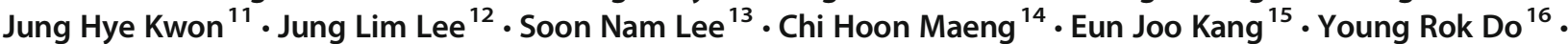 Yoon Seok Choi ${ }^{17} \cdot$ Kyung Hae Jung ${ }^{18}$}

1 Department of Biomedical Science, Seoul National University College of Medicine, 103 Daehak-ro, Jongno-gu, Seoul 110-799, South Korea

2 Department of Family Medicine, Seoul National University College of Medicine, Seoul, South Korea

3 Department of Biomedical Informatics, Seoul National University College of Medicine, Seoul, South Korea

4 Public Health Medical Service, Seoul National University Hospital, Seoul, South Korea

5 Department of Internal Medicine, Seoul National University Hospital, Seoul, South Korea

6 National Cancer Control Institute, National Cancer Center, Goyang, South Korea

7 Department of Internal Medicine, Seoul National University Bundang Hospital, Seoul National University College of Medicine, Seongnam, South Korea

8 Division of Hematology and Medical Oncology, Department of Internal Medicine, Chonnam National University School of Medicine, Hwasun, South Korea

9 Division of Hematology/Oncology, Chonbuk National University Medical School, Jeonju, South Korea
10 Department of Internal Medicine, Postgraduate Medical School, Gyeongsang National University, Jinju, South Korea

11 Department of Internal Medicine, Kangdong Sacred Heart Hospital, Hallym University College of Medicine, Seoul, South Korea

12 Department of Hemato-oncology, Daegu Fatima Hospital, Daegu, South Korea

13 Department of Internal Medicine, EwhaWomans University College of Medicine, Seoul, South Korea

14 Department of Medical Oncology and Hematology, Kyung Hee University Hospital, Seoul, South Korea

15 Department of Internal Medicine, Korea University Guro Hospital, Seoul, South Korea

16 Department of Internal Medicine, Dongsan Medical Center, Keimyung University School of Medicine, Daegu, South Korea

17 Department of Internal Medicine, Chungnam National University Hospital, Daejeon, South Korea

18 Department of Oncology, Asan Medical Center, University of Ulsan College of Medicine, Seoul, South Korea 